\title{
Use of chest radiographs in epidemiological investigations of pneumoconioses
}

\author{
Karen B Mulloy, David B Coultas, Jonathan M Samet
}

\begin{abstract}
The International Labour Organisation (ILO) classification of radiographs of pneumoconioses was developed to limit variation in classification of parenchymal abnormalities. In this study the manner in which chest radiographs were interpreted in 134 investigations reported in four peer reviewed journals during the five year period 1985-90 was examined. The approach for applying the ILO system was poorly described in most studies. For example, of 86 investigations using more than one reader, $66.3 \%$ described the method of reconciliation, but methods were not consistent among investigations. Our results indicate a number of potential problems in application of the ILO system, and gaps in existing recommendations that should be considered.
\end{abstract}

\section{(British Journal of Industrial Medicine 1993;50:273-275)}

Classification of the pneumoconioses is based on the presence of characteristic patterns on chest radiographs. Interpretation of chest radiographs for pneumoconioses is, however, subject to limitations posed by film quality and to substantial intra and interobserver variability. $^{1-5}$ The International Labour Organisation (ILO) system was developed to limit variation in interpretation of chest radiographs, but numerous studies of inter and intraobserver variability of observers trained in the system have documented persistent observer effects. . $^{3-5}$

These studies, however, have not considered the manner in which the ILO system is applied. In this study we examined 134 investigations of pneumo-

Department of Family and Community Health, Division of Occupational and Environmental Health, Marshall University School of Medicine, Huntington, West Virginia 25755, USA

K B Mulloy

Departments of Medicine and Family and Community Medicine, and the New Mexico Tumour Registry, Cancer Center, University of New Mexico Medical Center, Albuquerque, New Mexico 87131, USA

D B Coultas, J M Samet conioses reported in four peer reviewed journals from 1985 to the end of 1990. Each report was examined for the system of radiographic interpretation, the training of those reading radiographs, and the methods used for reading.

\section{Methods}

The 134 investigations were selected from four peer reviewed journals that often publish manuscripts on occupational lung diseases. Relevant articles were selected from a review of the table of contents of all issues of four journals in a five year period: American Review of Respiratory Disease, September 1985October 1990 (18.7\%); British Journal of Industrial Medicine, September 1985-September 1990 (40.3\%); Journal of Occupational Medicine, September 1985-October 1990 (14.9\%); American Journal of Industrial Medicine, Vol 8 Nos 1-6 1985-Vol 18 Nos $1-41990(26 \cdot 1 \%)$. Articles were included in the study if chest radiography was part of the research protocol.

Information on the method of interpretation was abstracted with a standardised form developed for this investigation (available on request). The items covered were (1) system for radiographic classification, (2) number and training of those reading the radiographs, (3) use of standard radiographs for comparison, (4) randomisation of radiograph order, (5) use of control radiographs to examine inter and intrareader variability of readings, (6) blinding of readers to subjects' exposure state, and (7) method for reconciliation of interreader differences.

With the standardised form, this information was collected by one of us (KBM) from all manuscripts. A random one third sample was reviewed by JMS and DBC. Major discrepancies between the two reviews in this sample were then re-examined by KBM in all 134 manuscripts and appropriate corrections made. The data were analysed with standard programs of the Statistical Analysis System. ${ }^{7}$

\section{Results}

The numbers of readers interpreting the chest radiographs were described in $77.6 \%$ of the 134 articles, and the types of readers in $35.1 \%$. Among 
Table 1 Description of methods for interpretation of chest radiographs among 111 investigations using a version of the ILO system, 1985-90

\begin{tabular}{lll}
\hline Method & Yes (\%) & $\begin{array}{l}\text { No or } \\
\text { not stated (\%) }\end{array}$ \\
\hline Randomisation & $23 \cdot 4$ & $76 \cdot 6$ \\
Blind to worker exposure & $41 \cdot 4$ & $58 \cdot 5$ \\
Use of ILO standard films & $13 \cdot 5$ & $86 \cdot 5$ \\
Use of control films & $12 \cdot 6$ & $87 \cdot 4$ \\
Method to examine repeatability & $2 \cdot 7$ & $97 \cdot 3$ \\
\hline
\end{tabular}

Table 2 Methods for reconciliation of reader differences in interpretation of chest radiographs among 57 investigations, 1985-90

\begin{tabular}{lc}
\hline Method & $\%$ \\
\hline Median & $33 \cdot 4$ \\
Consensus & $22 \cdot 8$ \\
Average & $14 \cdot 0$ \\
Majority & $14 \cdot 0$ \\
Most experienced reader & $12 \cdot 3$ \\
Other & 3.5 \\
\hline
\end{tabular}

the 104 manuscripts reporting the number of readers, $17 \cdot 3 \%$ reported one, $21 \cdot 2 \%$ two, $42 \cdot 7 \%$ three, and $18 \cdot 8 \%$ more than three.

The system used for radiographic interpretationthat is, categorisation of small and large opacities of pleural abnormalities and of other abnormalities, was detailed in 118 studies $(88.1 \%)$. Of these, the ILO1980 version was used in $72 \cdot 9 \%$. Other versions, primarily ILO-1971, were used in $21 \cdot 2 \%$. Methods other than the ILO system were used in $5.9 \%$.

Because formal programmes for training in the use of the ILO system have been available since $1971,{ }^{8}$ we examined articles for a description of the training or experience of readers in the use of the system. Of 111 articles that described the use, $31.5 \%$ used some or all $B$ readers certified by the National Institute for Occupational Safety and Health, $28 \cdot 8 \%$ used readers experienced with the ILO system, and $39.6 \%$ did not explicitly state the training or experience of the readers.

For those investigations using a version of the ILO system, we examined the process for reading the chest radiograph (table 1). Fewer than $50 \%$ of the papers mentioned the details of film reading. Blinding of the readers to workers' exposures was most frequently stated. Formal methods for assessing repeatability were rarely described.

Although the variability of interpretations of chest radiographs between readers has long been recognised, results relevant to this issue were not consistently reported, nor were methods for resolving the differences consistent among investigations (table 2). Of the 86 investigations using more than one reader, reconciliation of reader differences was described in
$66.3 \%$ (table 2); however, the methods for resolving the differences varied widely. The magnitude of reader variability was described in only 28 of the 86 investigations.

\section{Discussion}

Although guidelines have been developed to standardise the use of chest radiographs in epidemiological investigations, ${ }^{69}$ we found incomplete documentation of the application of the ILO or other systems in recent reports. The investigations reviewed in this study were largely conducted during an era when the importance of standardisation was widely documented and well recognised by investigators. Nevertheless, we found inadequate reporting of methodology, a fact that may reflect inadequate implementation of standardised procedures by investigators. Because our review examined only the information provided in publications, the findings may not fully represent the methods employed by the researchers. The lack of consistency in the methods among those investigations, however, presents a problem.

Because of variability in the interpretation of chest radiographs, guidelines of the Epidemiology Standardisation Project of the American Thoracic Society ${ }^{9}$ propose that at least two readers should interpret films, and that interreader and intrareader variability should be examined; the ILO-1980 guidelines strongly recommend at least two and preferably three independent readings. Among the investigations that we examined, only a few $(17 \cdot 3 \%)$ used a single reader, which suggests general compliance with these recommendations; however, for $22.4 \%$, the number of readers who interpreted the chest radiographs was not given. We suggest that compliance with the guidelines should always be documented in publications.

For the 86 investigations using more than one reader, 29 reports made no mention of the handling of observer variability. In the remaining 57 , there was little consistency in approaches for resolving differences among readers (table 2). This lack of standardisation may partly reflect the absence of specific recommendations on this issue by the $\mathrm{ILO}^{6}$ and the American Thoracic Society. ${ }^{9}$

Our results indicate a number of potential problems in the application of the ILO system for reading chest radiographs. Inadequate reporting of methods was common. Although our review could only document inadequacies of published reports, we surmise that the reports are indicative of problems in the actual methodology. We suggest that gaps in existing recommendations for applying the ILO system should be considered and the standardisation extended to cover the deficiencies identified in our review of recent studies. Research will be needed as the basis for any new recommendations. 
This research was supported in part by a contract from Miners' Colfax Medical Center, Raton, New Mexico. Dr Coultas is recipient of a First Award, R29 HL40587, and a Preventive Pulmonary Academic Award, K07HL02474, from the National Heart, Lung, and Blood Institute.

Requests for reprints to: Karen B Mulloy, DO, Marshall University School of Medicine, Department of Family and Community Health, 1801 6th Avenue, Huntington, West Virginia, 25755, USA.

1 Reger RB, Smith CA, Kibelstis JA, Morgan WKC. The effect of film quality and other factors on the roentgenographic categorization of coal workers' pneumoconiosis. American Journal of Roentgenology, Radium Therapy, and Nüclear Medicine 1972;115:462-72.

2 Musch DC, Higgins ITT, Landis JR. Some factors influencing ínterobserver variation in classífyíng símple pneumoconíosís. Br J Ind Med 1985;42:346-9.

3 Attfield MD, Althouse R, Reger RB. An investigation of interreader variability among $\mathrm{x}$-ray readers employed in the underground coal miner surveillance program. Annals of the American Conference of Governmental Industrial Hygienists 1986;14:401-9.

4 Ducatman AM, Yang W, Forman SA. 'B-readers' and asbestos medical surveillance. J Occup Med 1988;30:644-7.

5 Parker DL, Bender AP, Hankinson S, Aeppli D. Public health implications of the variability in the interpretation of ' $B$ ' readings for pleural changes. J Occup Med 1989;31:775-80.

6 International Labour Organisation. Guidelines for the use of ILO international classification of radiographs of pneumoconioses. Revised ed. Geneva: International Labour Office, 1980. (ISBN 92-2-102463-6 (Occupational safety and health series No 22 , revised).

7 SAS Institute. SAS users' guide: statistics. 5th ed. Cary, NC: SAS Institute Inc, 1985.

8 Morgan RH, Donner MW, Gayler BW, Margulies SI, Rao PS, Wheeler PS. Decision processes and observer error in the diagnosis of pneumoconiosis by roentgenography. American Journal of Roentgenology, Radium Therapy, and Nuclear Medicine 1973;117:757-64.

9 American Thoracic Society. Health effects of air pollution. New York: American Lung Association; 1978:1-63.

Accepted 8 June 1992

\section{Destruction of manuscripts}

From 1 July 1985 articles submitted for publication will not be returned. Authors whose papers are rejected will be advised of the decision and the manuscripts will be kept under security for three months to deal with any inquiries and then destroyed. 